\title{
Contribution to the Study of Aquatic Macrophytes from Musura Bay (Danube Delta, Romania)
}

\author{
Daciana Sava, Manuela Diana Samargiu and Gabriela Mihaela Paraschiv \\ Department of Natural Sciences, Faculty of Natural and Agricultural Sciences, Ovidius University, Constanta 900470, Romania
}

\begin{abstract}
Danube Delta - a unique, young and continuing growing region, is a favorable place for developing a unique flora and fauna with many rare and protected species in Europe. Even though the terrestrial environment is present in the area, the predominance of the aquatic environment led to the existence of a particular macrophytic flora. At the contact point of the sea-water and freshwater, physical, chemical and biological processes occur. As a consequence, researchers consider these coastal waters special ecosystem, in which Musura bay is the most representative one. The purpose of this paper is to contribute to the study of aquatic submerged and floating macrophytes. The present study took place over two years (2013-2014). In each year, a number of expeditions were made in different seasons in order to observe the diverse flora and flora associations. This due to seasonal variation in water quality, and might be a significantly seasonality of the vegetation also. The importance of the studies regarding flora of the Danube Delta, consist in the fact that the plants in this area are of social and economical importance, but also very important for environmental conservation.
\end{abstract}

Key words: Danube Delta, Musura bay, aquatic macrophytes.

\section{Introduction}

Danube Delta - the Romania's youngest relief unit is a particular territory and a favorable place for developing a unique flora and fauna with many rare and protected species in Europe. It is an area of approximately $3.466 \mathrm{~km}^{2}$, representing $1.5 \%$ of the Romanian territory, live around $1 / 3$ of all species of the Romanian flora (around 1,000 species) [1].

The great biodiversity of Danube Delta is considered to be in a better state than in other deltas from Europe, and it contains a great range of lower and higher plants, invertebrates, vertebrates and habitat types. Many of these species that live here are unique. In this category, plants as well as animals are included [2]. The particular and diverse conditions of the Danube Delta led to the establishment of rich and diversified vegetation. There is terrestrial vegetation on smaller surfaces, which encompasses the vegetation of riverside coppices or sandbanks. Also, there is vegetation specific to wet or dry sands, while

Corresponding author: Daciana Sava, associate Ph.D., main research fields: botany and environmental protection. the salty lands or marine sands developed a halophilic or subhalophilic flora (depending on the maximum salinity). A rich vegetation with aquatic or palustrine species develops on the lands with permanent water, excess humidity or, on the contrary, with low humidity. Both the flora and the vegetation of the Danube Delta were studied by numerous botanists, being published in over 300 scientific articles beginning with the 1990s. According to the existing data, it is considered that approximately 955 species of spontaneous cormophytes live in the delta and 157 vegetal associations have been identified so far $[3,4]$. The study of the flora and vegetation of the Danube Delta represents an important component of the biodiversity of the area in general and the issue regarding environmental protection $[5,6]$.

The aquatic and palustrine vegetation of the delta are considered the most representative ones. As a result, it was the most studied. And in this context, the purpose of this paper is to contribute to the study of aquatic macrophytes, both submerged and floating flora that has been studied in previous years, which is 
a constant preoccupation of researchers.

According to the adaptation to water, there are hydrophilic and helophilic vegetation.

The hydrophilic vegetation is represented by aquatic plants and here are the following categories:

- Flora of fresh running waters - represented by a few number of species, but numerically abundant. These species live on channels and streams with reduce water flow or small lakes with slow water circulation;

- Flora of fresh stagnant waters - these species live in open-pools (with natural active water exchange) or closed pools, which are smaller and with slow water circulation;

- Flora of brackish and salty waters - this kind of flora is very poor, because mainly the water in inner Delta is fresh water [1].

The helophilic vegetation is the most distributed and it is represented by a large number of species and individuals. This type of flora lives on lake shores, streams, channels and shallow pools.

\section{Material and Methods}

The present study took place over two years, 2013-2014. In each year, a number of expeditions were made in different seasons in order to observe the diverse flora and flora associations. Due to seasonal variation in water quality, there might be a significantly seasonality of the vegetation also. The present observations took place in Musura bay (Fig. 1).

Musura bay or Northern bay is situated north of Sulina distributary, between Sulina and the southernmost arm of the Chilia distributary, Stary Stambul. It has a length of about $12 \mathrm{~km}$, crossed by the border between Romania and Ukraine and has a very low, marshy coast.

Now, in the Romania Danube Delta biosphere reserve, there are only two areas with brackish habitat: between the Sacalin Peninsula and the Danube Delta coast-Musura bay. But both are now in the process of undergoing a change of status. The Sacalin
Peninsula will disappear so that the habitat will become a marine [2].

For the Musura bay, as result of the sedimentation of sandy sediments derived from the Stary Stambul secondary mouth and transported by the longshore current from the north, a submerged littoral bar was formed in Ukrainian waters near the Romanian-Ukrainian border. During the late 1970s through to the beginning of the 1980s, this became a lateral spit with a length of about $3.5 \mathrm{~km}$ in 1985 . At the beginning of the 1990s, the new island length was already sufficiently long to cross the border between Ukraine and Romania. Subsequently, the island advanced to the south for about $3 \mathrm{~km}[7,8]$.

In its present position, the new spit (approximately $7 \mathrm{~km}$ in length and $80 \mathrm{~m}$ wide) has transformed the previous Musura bay into a lagoon with two inlets (north and south of the former bay).

\section{Results and Disscution}

Due to the field trips that took place in spring, summer and autumn in year 2013 and 2014, the following taxa were identified in the study area.

Aquatic vegetation: emersed, attached or not attached to a substrate-Pteridophyta: Salvinia natans (L.) All. T., Euras., Angiospermatophyta: Hydrocharis morsus-ranae L., H., Euras., Lemna minor L. Hd, Cosm., Lemna trisulca L., Hd, Cosm., Nuphar luteum Sm., Hd, Euras. (Fig. 2), Nymphaea alba L., Hd, Eur. (Fig. 2), Nymphoides peltata Kuntze, Hd, Euras., Potamogeton crispus L., Hd, Cosm., Potamogeton natans L., Hd, Circ., Potamogeton pectinatus L., Hd, Cosm., Potamogeton perfoliatus L., Hd, Cosm., Stratiotes aloides L., Hd, Euras., Trapa natans L., T., Euras. Cont (submedit) (Fig. 3) and Utricularia vulgaris L., Hd, Circ..

This type of vegetation is characteristic to the basins with deposits of suspensions, with more or less oxygenized waters. In some cases, this vegetation can be encountered in pools with stronger clogging. The flora that makes up this vegetation develops at the 


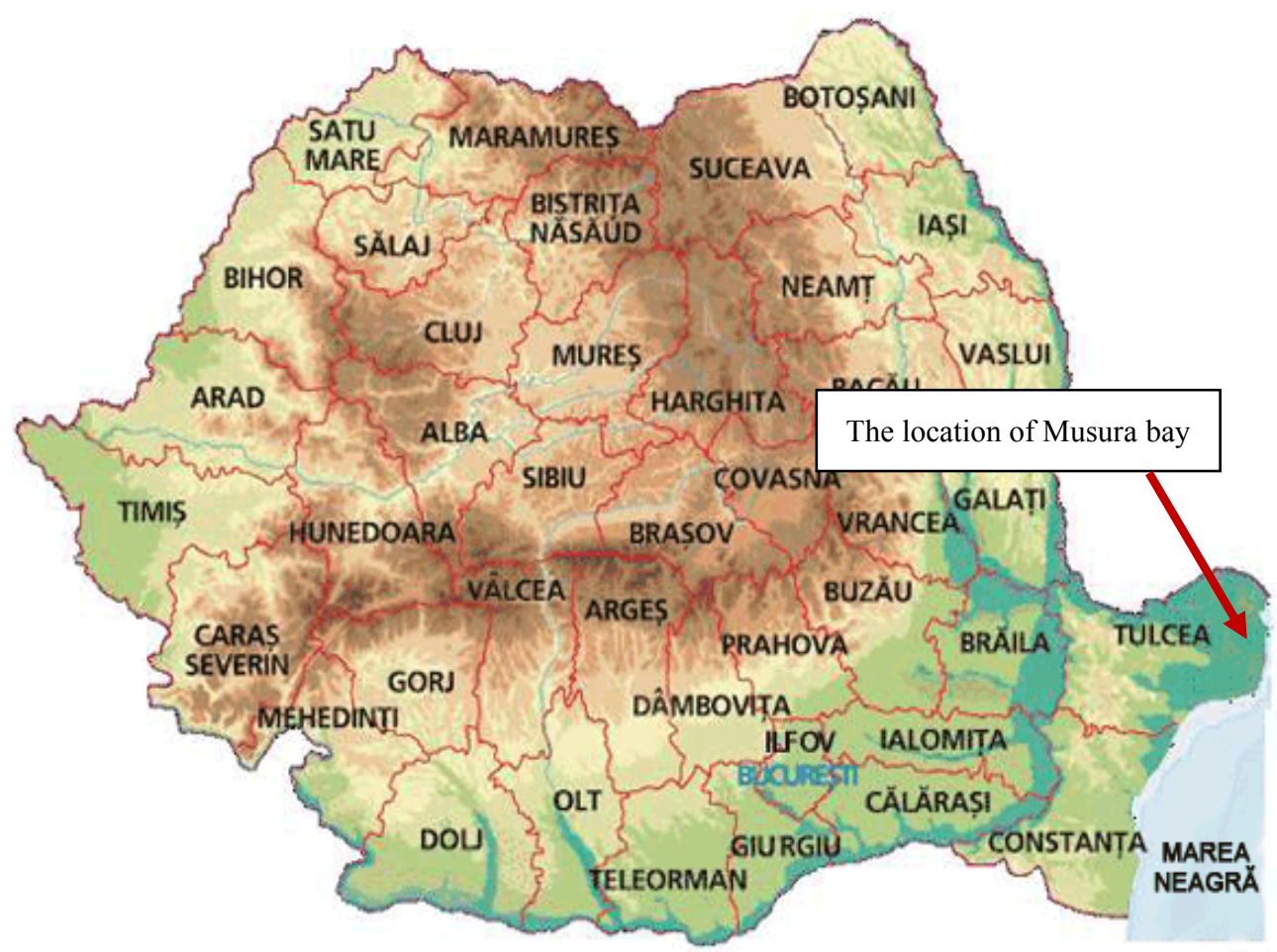

(a)

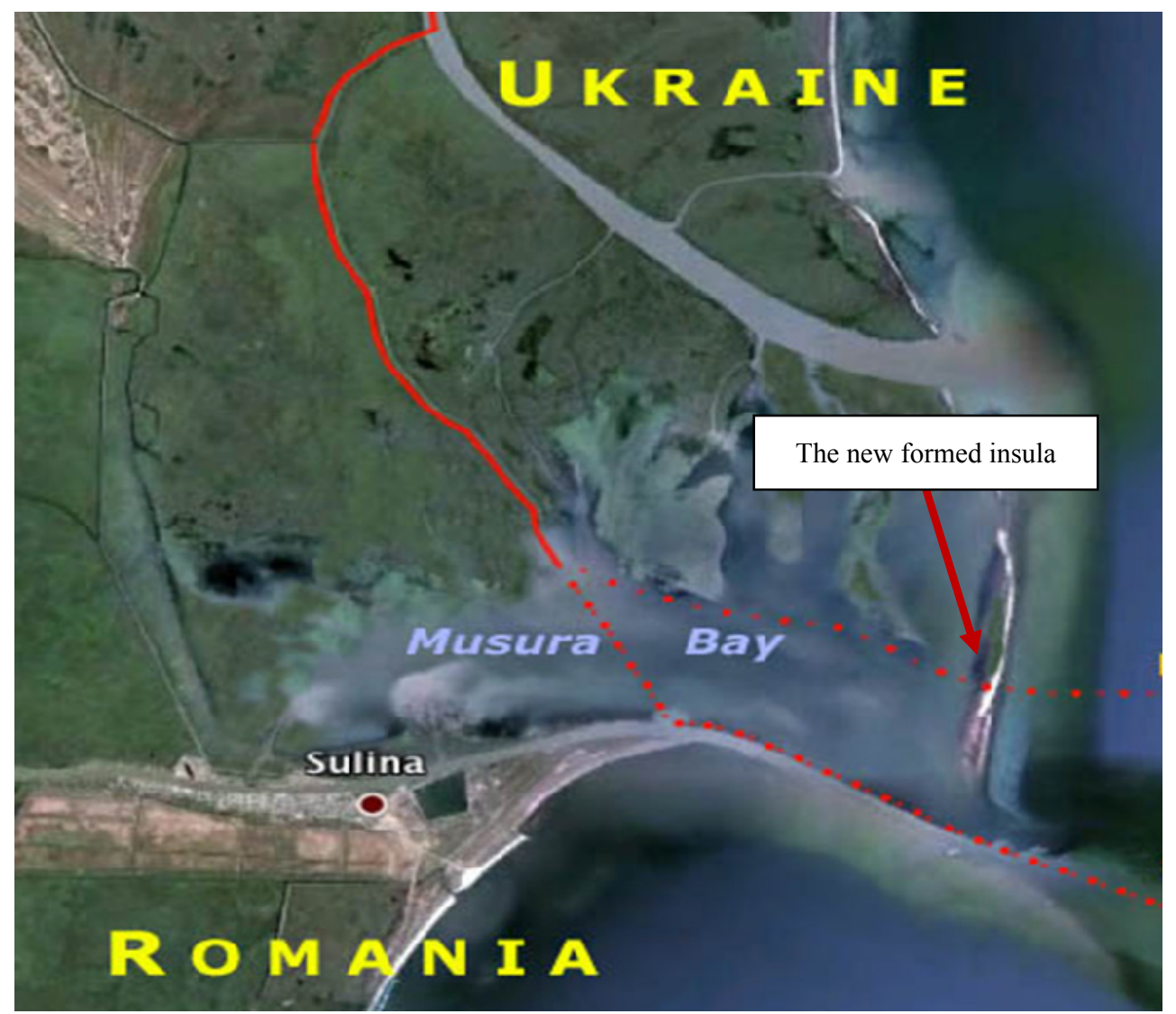

(b)

Fig. 1 The location of Musura bay in the eastern part of Romania (a) and in Danube Delta region (b). 


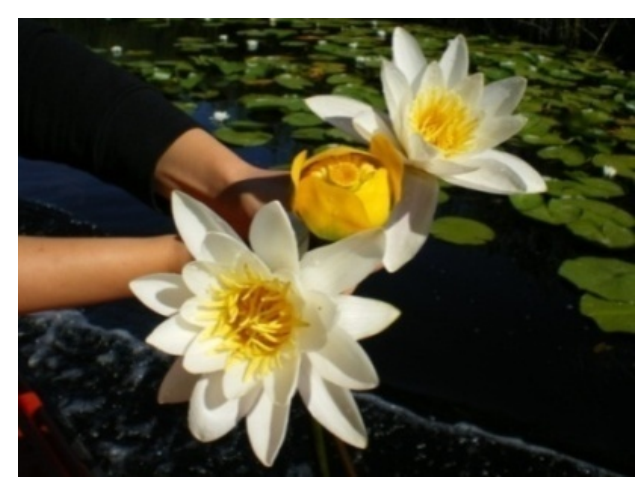

Fig. 2 Nuphar luteum and Nyphaea alba.

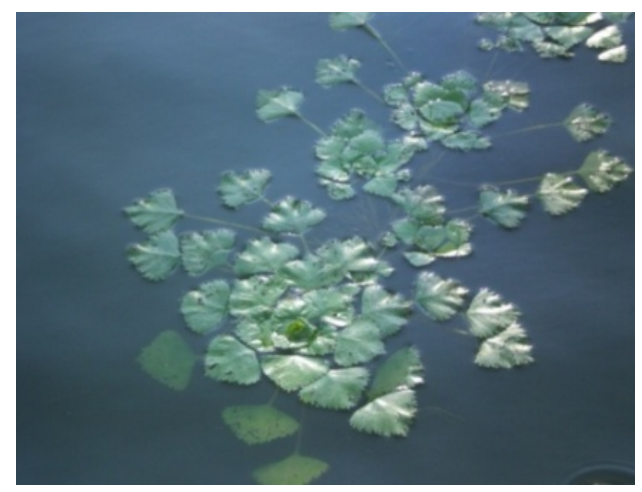

Fig. 3 Trapa natans.

surface of still waters in sheltered pools, sometimes smaller where the currents are weak or along the channels with calm waters.

In the pools with stronger anthropogenic influence, Lemna trisulca develops abundantly. The species of Potamogeton are widely distributed in the Danube Delta, but the great occurrence of Potamogeton crispus indicates a stronger anthropogenic influence, which leads to an oxygen deficit and accumulation of organic materials in the respective pools. The related species, Potamogeton pectinatus, develops well where oxygenation is scarce, accumulating a great amount of biomass and leading to the clogging of the pools. Stratiotes aloides is very distributed in aquatic basins with calm waters, vegetating in clogged places sheltered from strong winds. Sometimes, the species may invade the pools where fishing is practiced. Practically, it becomes harmful due to the amount of biomass it produces (leads to decreased water oxygen, which harms fish farming). The association of the species Trapa natans is one of the most distributed in the marshes and lakes of the Danube Delta. In the specialized literature, it is mentioned that Trapa natans is practically ever-present in the Danube Delta aquatic basins, producing phytocoenoses on considerable surfaces. However, it seems that the draining of certain lakes and marshes along the Danube, as well as the presence of toxic substances, led to the strong reduction of the populations of Trapa natans, the species being listed as "vulnerable" (VU) in the "Romanian Red List of Vascular Plants" (1994) according to the IUCN categories. Utricularia vulgaris is a plant with mixotrophic nutrition which develops in shallow waters, strongly clogged and rich in decomposing organic substances, its mass occurrence indicating a strong eutrophication of these pools. Its status in the "Romanian Red List of Vascular Plants" (1994) is "Rare" (R) according to the IUCN categories.

Submerged vegetation Magnoliophyta: Ceratophyllum demersum L., Hd, Cosm., Ceratophyllum submersum L., Hd, Eur., Elodea canadensis Michx., H, Adv., Myriophyllum spicatum L., H, Circ., Myriphyllum verticilatum L., H, Circ. and Najas marina L. T, Subcosm. Between the two species of Ceratophyllum, Ceratophyllum demersum seem to have a resistence to pollution, shown by its development in large quantities in some areas. Elodea canadensis is an adventive plant, which is original from North America and introduced into Central and Western Europe in the 20th century, being first mentioned in Romania in the Danube Delta. Initially, it developed intensely, but now it is not very widely distributed. It even disappeared from certain places and where it still exists, the populations are not numerous. Najas marina is characteristic to still water lakes or very slow flowing waters, with a preference for open places and more demanding in terms of light.

Palustrine vegetation-Magnoliophyta: Alisma plantago-aquatica L., Hd, Circ., Buttomus umbellatus L., Hd, Euras., Carex riparia Curtis, G, Euras, Cicuta virosa L., H, Euras., Lythrum salicaria L., H, Circ., 
Oenanthe aquatica (L.) Poir., T, Euras., Mentha aquatica L., H, Eur., Myosotis scorpioides L., H, Euras., Phragmites australis (Cav.) Trin. ex Steud., G, Cosm., Sagittaria sagitifolia L., Hd, Euras., Schoenoplectus lacustris (L.) Palla., G, Cosm., Sparganium erectum L., G, Euras., Rumex hydrolaphatum Huds., H, Eur., Typha angustifolia L., G, Circ. and Typha latifolia L., G, Cosm. Palustrine vegetation is most distributed in the Danube Delta. The characteristic vegetal formation is the reed plot, which occupies most of this territory. It is an association with durable consistency, which offers the characteristic aspect of most aquatic basins, developing both in clear waters and in waters with various clogging degree.

\section{Conclusions}

This recent study of the aquatic vegetation of the Musura bay shows a notable diversity. An analysis of the floristic elements (geoelements) was made, which shows the predominance of Eurasian and European elements (48\%), and a large number of cosmopolitan species (27\%). Circumpolar species represent $18 \%$ and adventives species only $3 \%$. Nevertheless, during the years, human actions can be observed in many ways. This may lead to changes in floristic aspects as well as in ecosystems in general. Many studies showed that there was a drastic reduction in taxonomic diversity, because over 100 species mentioned once in the literature (in 1950s) were not recorded in recent studies and on the other hand adventives species appear [1]. The research upon flora of the Danube Delta must be continued in the future on more field trips. An important part of this study must be the research on vulnerable and endangered species. The protection and preservation of the flora and vegetation of the Danube Delta is and must remain the most important part of the general preservation of the Delta ecosystems and the environment in the future.

\section{References}

[1] Ciocârlan, V. 2011. "Vascular Flora of the Danube Delta." Scientific Annals LVII (I): 41-64.

[2] Gâştescu, P., and Stiucă, R. 2008. Danube Delta - Biosphere Reservation. Constanța, România: Dobrogea Publising House.

[3] Ciocârlan, V. 2008. The Flora of Danube Delta-Cormophyta. Bucureşti: Ceres Publishing House.

[4] Popescu, A., Sanda, V., and Oroian Silvia. 1997. "The Vegetation of Danube Delta." Marisia XXV (suppl.): 3-126.

[5] Petrescu, M. 2007. Dobrogea and Danube Delta-Flora and Habitat Conservation. Tulcea: Eco-museal Research Institute.

[6] Sanda, V., and Popescu, A. 1973. "Researches Regarding the Flora and Vegetation from Danube Delta." Biological Studies and Researches, Botany Series 25 (5): 399-424.

[7] Stanică, A., Dan, S., and Ungureanu, V. G. 2007. "Costal Changes at the Sulina Mouth of the Danube River as a Result of Human Activities." Marine Pollution Bulletin 55: 555-563.

[8] Riza Rapport. 2002. "Vegetation of the Biosphere Reserve." Presented at "Danube Delta" with Transboundary Vegetation Map. 